A rarer form is as follows :-

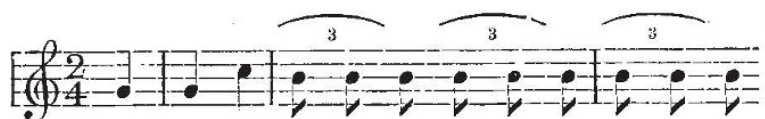

I have noticed that this latter form seems more difficult for the little musicians, one of whom in particular used to provoke me by singing the $B$ most outrageously flat. I have been accustomed to imitate these birds by whistling, and they very readily answer my whistle. In this way the different forms of their theme have become fixed in my memory.

W. L. Goodwin.

Queen's University, Kingston, Canada, November II.

\section{Who was Mr. Charles King?}

AMONG the ingenious in many considerable parts of the world, of whose undertakings, studies, and labours the Philosophical Transactions of the years $1700 \mathrm{sqq}$. gave some account, an able microscopist suddenly appears, of whose life and work one would lihe to have more accurate information than seems to be current. Perhaps a member of the Royal, or the Royal Microscopical, Society may be able to supply some particulars about this "Anglois anonyme," as Trembley calls him, and willing to assist in rescuing his name from an undeserved oblivion. His first contribution to the Philosophical Transactions-of very little importance indeed-is to be found in No. 266, for September and October I 7co, pp. 672-673, under the title, "A Letter from Mr. Charles King to Mr. Sam. Doudy, F.R.S., concerning Crabs Eyes ;" it is dated, "Little Wirley, Decemb. I4," and subscribed, "Ch. King." In the copy of the Transactions I have before me, a contemporary, who seems to have been tolerably well informed, has inserted divers MS. notes, remarks, and corrections; he added here the words, "Staffordshe." to the locality, and "Student of Ch. Ch. Oxon." to the subscription, which, as far as I know, does not recur in any of the subsequent Transactions. But under the title, "Two Letters from a Gentleman in the Country, relating to Mr. Leuwenhoeck's Letter in Transaction, No. 283, Communicated by Mr. C." (in No. 288, for November and December 1703, pp. I494-1501, with eight figures, text and illustrations being both equally remarkable for the period), the same hand has again inscribed the name of "Mr. Charles King," and filled up the blanks left on pages 1494 and 1495 by the initials "W." and "W. Ch. Esq." with the additions of "irley par. Com. Stafford" and "Walter Chetw... of Ingestry Staffords ." (the rest has been cut off by the binder of the volume), so that there remains no reasonable doubt as to the truth of the identification. Now we read in the second of these letters from the country, dated "July 5, r703," p. I50r, "But of those" (viz. animalcula) "(among other things) I last year gave an account to Sir Ch. Holt, which I hear will shortly be publish'd in the Transactions." I don't think it is bold to conjecture that the account here alluded to had already been published, and is, in fact, the article printed in No. 284, for March and April 1703, pp. I 357 (bis)-1372 (with excellent figures on the plate accompanying that number), under the title of "An Extract of some Letters sent to Sir C. H. relating to some Microspocal" (sic) "Observations. Communicated by Sir C. H. to the Publisher" (II. Sloane); and no doulit these epistles may also be ascribed to the same anonymous gentleman.

In all the above-mentioned letters we have some early and first-rate contributions to microscopical science, the importance of which had been shortly before so evidently demonstrated by the wonderful discoveries made by the improved magnifyingglasses.

Queritur: Who was Mr. Charles King?

$\mathrm{S}$.

The Hague, November 27.

\section{NOTE ON A PROPOSED ADDITION TO THE VOCABULARY OF ORDINARY ARITHMETIC:}

$T \mathrm{HE}$ total number of distinct primes which divide a 1 given number I call its Manifoldness or Multiplicity.

${ }^{1}$ Perhaps I may without immodesty lay claim to the appellation of the Mathematical Adam, as I believe that I have given more names (passed into general circulation) to the creatures of the mathematical reason tran all the other mathematicians of the age combined.
A number whose Manifoldness is $n \mathrm{I}$ call an $n$-fold number. It may also be called an $n$-ary number, and for $n=\mathrm{I}, 2,3,4, \ldots$ a unitary (or primary), a binary, a ternary, a quaternary, ..... number. Its prime divisors I call the elements of a number; the highest powers of these elements which divide a number its components; the degrees of these powers its indices; so that the indices of a number are the totality of the indices of its several components. Thus, we may say, a prime is a one-fold number whose index is unity.

So, too, we may say that all the components but one of an odd perfect number must have even indices, and that the excepted one must have its base and index each of them congruous to $I$ to modulus 4 .

Again, a remarkable theorem of Euler, contained in a memoir relating to the Divisors of Numbers ("Opuscula Minora," vol. ii. p. 514), may be expressed by saying that every even perfect number is a two-fold number, one of whose components is a prime, and such that when augmented by unity it becomes a power of 2 , and double the other component. ${ }^{1}$

Euler's function $\phi(n)$, which means the number of numbers not exceeding $n$ and prime to it, I call the totient of $n$; and in the new nomenclature we may enunciate that the totient of a number is equal to the product of that number multiplied by the several excesses of unity above the reciprocals of its elements. The numbers prime to a number and less than it, I call its totitives.

Thus we may express Wilson's generalized theorem by saying that any number is contained as a factor in the product of its totitives increased by unity if it is the number 4 , or a prime, or the double of a prime, and diminished by unity in every other case.

I am in the habit of representing the totient of $n$ by the symbol $\tau n, \tau$ (taken from the initial of the word it denotes)

I It may be well to recall that a perfect number is one which is the half of the sum of its divisors. The converse of the theorem in the text, viz. that $2^{n}\left(2^{n+1}-1\right)$, when $2^{n+1}-1$ is a prime, is a perfect number, is enunciated and proved by Euclid in the 36 th (the last proposition) of the 9 th Book of the "Elements," the second factor being expressed by him in the sum of a geometric series whose first term is unity and the common ratio 2 . In Isaac Barrow's English translation, published in 1660 , the enunciation is as follows:- "If from a unite be taken how many numbers soever $1, A, B, C, D$, in double proportion continually, untill the whole added together $\mathrm{E}$ be a prime number; and if this whole $\mathrm{E}$ multiplying the last produce a number $\mathrm{F}$, that which is produced $\mathbf{F}$ shall be a perfect number."

The direct theorem that every even perfect number is of the above form could probably only have been proved with extreme difficulty, if at all by the resources of Greek Arithmetic. Euler's proof is not very easy to follow in his own words, but is substantially as follows:

Suppose P (an even perfect number) $=2^{n t} \mathrm{~A}$. Then, using in general $\mathrm{X}$ to denote the sum of the divisors of $\mathrm{X}$,

$$
\begin{gathered}
2=\frac{\int \mathrm{P}}{\mathrm{P}}=-\frac{2^{n} \cdot \int \mathrm{A}}{2^{n} \mathrm{~A}}=\frac{2^{n+1}-1}{2^{n}} \cdot \frac{\int \mathrm{A}}{\mathrm{A}} . \\
\int \frac{\mathrm{A}}{\mathrm{A}}=\frac{2^{n+1}}{2^{n+1}-1}, \text { say }=\frac{\mathrm{Q}+1}{\mathrm{Q}} .
\end{gathered}
$$

Hence

Hence $\mathrm{A}=\mu \mathrm{Q}$, and $\mathrm{A}=1+\mu+\mathrm{Q}+\mu \mathrm{Q}+\ldots$ (if $\mu$ be supposed $>1$ ). Hence unless $\mu=1$ and at the same time $Q$ is a prime

$$
\int \mathrm{A}>\mu(\mathrm{Q}+1)
$$

i.e. $\frac{\mathrm{A}_{\mathrm{A}}}{\mathrm{A}}$ is greater than itself.

Hence an even number $\mathbf{P}$ cannot be a perfect number if it is not of the form $2^{n}\left(2^{n+1}-1\right)$, where $2^{n+1}-1$ is a prime, which of course implies that $n+1$ must itself be a frime.

It is remarkable that Euler makes no reference to Euclid in proving his own theorem. It must always stand to the credit of the Greek geometers that they succeeded in discovering a class of perfect numbers which in al probability are the only numbers which are perfect. Reference is made to so-called perfect numbers in Plato's " Republic," H, 546 B, and also by Aristotle, Probl. I E 3 and "Metaph." A 5, which he attributes to Pythagoras, but which are purely fanciful and entitled to no more serious consideration than the late Dr. Cummings's ingenious speculations on the number of the Beast. Mr. Margoliouth has pointed our to me that Muhamad Al-Sharastani, in his "Book of Religious and Philosophical Sects," Careton. 1856, p. 267 of the Arabic text, assigns reasons for regarding all the numbers up to 10 inclusive as perfect numbers. My particular attention was called to perfect numbers by a letter from Mr. Christie, dated from "Carlton, Selby, containing some inquiries relative to the subject. 
being a less hackneyed letter than Euler's $\phi$, which bas no claim to preference over any other letter of the Greek alphabet, but rather the reverse.

It is easy to prove that the half of any perfect number must exceed in magnitude its totient.

Hence, since $\frac{3}{2} \cdot \frac{5}{4}$ is less than 2 , it follows that no odd two-fold perfect number exists.

Similarly, the fact of $\frac{3}{2} \cdot \frac{7}{6} \cdot \frac{\text { II }}{\text { IO }}$ being less than 2 is sufficient to show that 3,5 must be the two least elements of any three-fold perfect number; furthermore, $\frac{3}{2} \cdot \frac{5}{4} \cdot \frac{17}{16}$ being less than 2 , shows that I I or I 3 must be the third element of any such number if it exists ${ }^{1}$-each of which hypotheses admits of an easy disproof. But to disprove the existence of a four-fold perfect number by my actual method makes a somewhat long and intricate, but still highly interesting, investigation of a multitude of special cases. I hope, numine favente, sooner or later to discover a general principle which may serve as a key to a universal proof of the non-existence of any other than the Euclidean perfect numbers, for a prolonged meditation on the subject has satisfied me that the existence of any one such-its escape, so to say, from the complex web of conditions which hem it in on all sides-would be little short of a miracle. 'Thus then there seems every reason to believe that Euclid's perfect numbers are the only perfect numbers which exist!

In the higher theory of congrusnces (see Serret's "Cours d'Algèbre Supérieure") there is frequent occasion to speak of " a number $n$ which does not contain any prime factor other than those which are contained in another number M."

In the new nomenclature $n$ would be defined as $a$ number whose elements are all of them elements of $\mathrm{M}$.

As $\tau \mathrm{N}$ is used to denote the totient of $\mathrm{N}$, so we may use $\mu \mathrm{N}$ to denote its multiplicity, and then a well-known theorem in congruences may be expressed as follows.

The number of solutions of the congruence

is

$$
x^{-}-\mathrm{I} \equiv \circ(\bmod \mathrm{P})
$$

$2^{k \mathrm{P}}$ if $\mathrm{P}$ is odd,

$2^{\mu \mathrm{P}-x}$ if $\mathrm{P}$ is the double of an odd number,

$2^{\mu \mathrm{P}} \quad$ if $\mathrm{P}$ is the quadruple of an odd number,

and $2^{\mu \mathrm{P}+\mathrm{x}}$ in every other case.

In the memoir above referred to, Euler says that no one has demonstrated whether or not any odd perfect numbers exist. I have found a method for determining what (if any) odd perfect numbers exist of any specified order of manifoldness. Thus, e.g., I have proved that there exist no perfect odd numbers of the 1st, 2nd, $3 \mathrm{rd}$, or 4 th orders of manifoldness, or in other words, no odd primary, binary, ternary, or quaternary number can be at perfect number. Had any such existed, my method must infallibly have dragged each of them to light ${ }^{2}$

In connection with the theory of perfect numbers I have found it useful to denote $p^{i}-\mathrm{I}$ when $p$ and $i$ are left general as the Fermatian function, and when $p$ and $i$ have specific values as the $i$ th Fermatian of $p$. In such case $p$ may be called the base, and $i$ the index of the Fermatian.

1 3, 5, 7 can never co-exist as elements in any perfect number as shown by

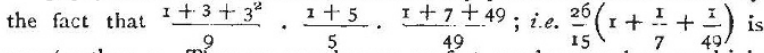
greater than 2. Thus we see that no perfect number can be a multiple of 105. So again the fact that $\frac{5}{4} \cdot \frac{7}{6} \cdot \frac{\mathrm{II}}{10} \cdot \frac{\mathrm{I}}{\mathrm{I2}} \cdot \frac{17}{16} \cdot \frac{19}{18}$ is less than 2 is sufficient to prove that any odd perfect number of multiplicity less than 7 must be divisible by 3 .

2 I have, since the above was in print, extended the proof to quinary numbers, and anticipate no difficulty in doing so for numbers of higher degrees of multiplicity, so that it is to be hoped that the way is now paved towards obtaining a general proof of this falmary theorem.
Then we may express Fermat's theorem by saying that either the Fermatiun itself whose index is one unit below a given prime or else its base must be divisible by that prime. ${ }^{1}$

It is also convenient to speak of a Fermatian divided by the excess of its base above unity as a Reduced Fermatian and of that excess itself as the Reducing Factor.

The spirit of my actual method of disproving the existence of odd perfect numbers consists in showing that an $n$-fold perfect number must have more than $n$ elements, which is absurd. The chief instruments of the investigation are the two inequalities to which the elements of any perfect number must be subject and the properties of the prime divisors of a Reduced Fermatian with an odd prime index.

New College, November 28.

J. J. Sylvester.

\section{COUTTS TROTTER.}

A GREAT calamity has fallen on the University of A Cambridge and on Trinity College, and many men differing widely in their interests and callings are bearing together the burden oi a common sorrow in the knowledge that the Rev. Coutts Trotter, the Vice-Master of Trinity College, was no more. Mr. Trotter suffered from a severe and prolonged illness during last winter and early spring, and though in the summer he seemed to have almost regained his health, he began as the year advanced once more to lose ground. When he returned from abroad in October his condition gave rise to great anxiety among his friends; as the term went on he grew worse rather than better; and an attack of inflammation of the lungs rapidly brought about the end, which took place in his rooms in College, in the early morning of Sunday, December 4.

During the last twenty of the fifty years of Mr. Trotter's life both the University of Cambridge and Trinity College have undergone great and important changes. In bringing about these changes $\mathrm{Mr}$. Trotter had a great share, perhaps a greater share than any other individual member of the University; and while those changes are probably neither wholly good nor wholly evil, but good mixed with evil, no one hand, as the changes were being wrought, did so much good and so little evil as his. A wide and yet accurate knowledge of many different branches of learning, a genuine sympathy with both science and scholarship, a judicial habit of mind which enabled him to keep in view at the same time broad issues and intricate details, a clear insight into the strength and weakness of academic organization, and a singular skill in drafting formal regulations, - these qualities, aided by a kindly courtesy which disarmed opponents, and a patience which nothing except perhaps coarse rudeness could ruffle, enabled him in his all too short life to do for his College and for his University more than it seemed possible for one man to do.

The academic labours which thus year by year increased upon him, though they in many ways, both directly and indirectly, tended to the advancement of science, became, increasingly, hindrances to his pursuing actively any special path of scientific inquiry, as he had once hoped to do. His love of science began with his boyhood, while he listened to the Royal Institution lectures of Faraday. Having taken a degree, with honours in both classics and mathematics, and having obtained a Fellowship at Trinity, he gave up to scientific study much of the leisure thus afforded to him : and, in order more thoroughly to train himself, spent the best part of two years at Heidelberg, during a portion of which time he was engaged in physiological research under Helmholtz. He acquired a very

${ }^{x}$ So to we may state the important theoren that if an element of a mast be its square. 